九州大学学術情報リポジトリ

Kyushu University Institutional Repository

Cytogenetics of Ditelosomic Alien Addition Lines in rice (Oryza sativa L.) Each Carrying an Extra Pair of Telocentric Chromosomes of 0 . punctata Kotschy

Yasui, Hideshi

Plant Breeding Laboratory, Faculty of Agriculture, Kyushu University

Iwata, Nobuo

Plant Breeding Laboratory, Faculty of Agriculture, Kyushu University

https://doi.org/10.5109/24243

出版情報: 九州大学大学院農学研究院紀要. 43 (1/2)，pp.1-9，1998-11. Kyushu University バージョン：

権利関係 : 


\title{
Cytogenetics of Ditelosomic Alien Addition Lines in rice (Oryza sativa L.) Each Carrying an Extra Pair of Telocentric Chromosomes of $O$. punctata Kotschy
}

\author{
Hideshi Yasui and Nobuo Iwata \\ Plant Breeding Laboratory, Faculty of Agriculture, Kyushu University, \\ Fukuoka 812-8581, Japan \\ (Received February 24, 1998 and accepted August 7, 1998)
}

\begin{abstract}
Ditelosomic alien addition lines (DtAALs: $2 \mathrm{n}=2 \mathrm{x}+2 \mathrm{t}$ ) of rice each carrying a pair of telocentric chromosomes of Oryza punctata were isolated at low frecuencies (2.5-11.1\%) from the progenies of respective monotelosomic alicn addition lines (MLALs: $2 n=2 \mathrm{x}+1 \mathrm{t}) 7,11$ and one unidentificd MLAAJ. During the mciosis, the alien telocentric chromosomes of three DTAALs completely paired at the pachytene and usually separated to each daughter cell at anaphase I, giving rise to viable gametes with an alien telocentric chromosome at high frequencies. These DtAALs were characterized by stable transmission of the alien telocentric chromosome in the progenies. The transmission rates of the alien chromosome were considerably high in the DtAALs, and most plants of their self-pollinated progeny carried at least one alien telocentric chromosome. The pollen and seed fertility were different among threc DtANIs. DtAAL 11 carrying a short telocentric chromosome of $O$. punctata showed high pollen and sced fertility similar to the disomics. The Dt.AALs showed relatively stable transmission of alien telocentric chromosome(s), where gametes with an extra telocentric: chromosome are functional in both female and male germ cells. These suggest that small chromosome fragment with functional centromere, that is a telocentric chromosome, can be transmitted to the progenies and be stable in the next generation. High transmission rates of the alien telocentric chromosome in these DtAALs assure the efficient changes in genctic background of any recipient cultivars by backcrossing.
\end{abstract}

\section{INTRODUCTION}

Disomic alien addition lines (DAALs: $2 \mathrm{n}=2 \mathrm{x}+2)$ and ditelosomic alien addition lines (DtAALs: $2 n=2 x+2 t$ ) can be used to introduce alien traits because a pair of alien chromosomes normally form a bivalent at meiosis and at least a copy of that alien chromosome is transmitted to the whole progeny of the next generation. The meiotic chromosome behavior and the transmission of the alien chromosome in the offsprings of $D(t) A A L s$ have been observed in several species such as wheat (Riley and Chapman 1958) and beet (Lange et al., 1993). These D(t)AALs in polyploid species could tolerate the condition harboring an extra pair of alien chromosomes in addition to the normal complement and produced viable progenies. In diploid species, several tetrasomics can often tolerate the presence of an extra pair of chromosomal fragments in addition to the diploid complement and produce viable progenies as in barley (Fedak and Helgason 1970, Tsuchiya 1969, Wiebe 1975) and rice (Yasui et al., 1995).

In this study, rice plants each carrying an extra pair of alien telocentric chromosomes in addition to 24 chromosomes (DtAALs) were obtained at low frequencies in the self-pollinated progenies of three MtAALs and analyzed for the genetic basis by observing morphology, cytology, seed and pollen fertility and alien chromosome transmission. 


\section{MATERIALS AND METHODS}

\section{Plant materials}

Three DtAALs ( $n=2 x+2 t)$ of rice each carrying an extra pair of telocentric chromosomes of Oryza punctata Kotschy were isolated in the self-pollinated progenies of the three MtAALs X, 7 and 11. MtAAL 7 and MtAAL 11 had been isolated from the progenies of monosomic alien addition line (MAAL) 7 (Type I) and MAAL 11, respectively (Yasui and Iwata, 1998). MtAAL X had been isolated from the progenies of an unidentified MAAL (MAAL X) with green leafhopper resistance. In the self-pollinated progenies of the three MtAALs, the morphological features of the segregants were investigated at maturity. The plants showing deviated morphological features were isolated on the basis of morphological difference from those of disomics and parental MtAALs. These isolated DtAALs were studied to identify the extra pair of alien chromosomes and characterize their morphological and reproductive features.

\section{Cytological analysis}

Chromosome number of the aberrants were determined from root tip tissues. The plants discriminated by morphological deviation from disomics were used for mitotic chromosome analysis. The plants presumed as DtAALs were subsequently investigated at the diakinesis and metaphase I of PMCs by the acetocarmin squash methods. The telocentric chromosome was designated as small letter " $t$ " in the meiotic chromosome configuration such as $12 \pi+1$ tा or $12 \pi+2 \mathrm{t}$.

\section{Characterization of DtAALs}

Pollen and seed fertility of the DtAALs were investigated at heading stage and after harvesting, respectively. The transmission rates of extra alien chromosomes were examined from the rates of segregating M1AALs and DtAALs characterized by their respective morphological features such as grain shape.

\section{RESULTS}

\section{Isolation and identification}

The three MtAALs were unstable and gave rise to the respective DtAALs at a range

Table 1. Frequency of DtAALs in the self pollinated progenies of the three MtAALs each carrying an $O$. punctata teloentric: chromosomes.

\begin{tabular}{|c|c|c|c|c|c|}
\hline \multirow{2}{*}{$\begin{array}{l}\text { Parental } \\
\text { MtAAL }\end{array}$} & \multirow{2}{*}{$\begin{array}{l}\text { The number } \\
\text { of plants } \\
\text { observed }\end{array}$} & \multicolumn{3}{|c|}{$\begin{array}{c}\text { The number of plants segregated } \\
\text { in the selfed progenies }\end{array}$} & \multirow{2}{*}{$\begin{array}{l}\% \text { of } \\
\text { DtAAE }\end{array}$} \\
\hline & & Normal & MtAAL & DtAAL & \\
\hline MtAAL X & 126 & 72 & 49 & 5 & 4.0 \\
\hline MtAAL 7 & 120 & 88 & 29 & 3 & 2.5 \\
\hline MtAAL 11 & $y$ & 5 & 3 & 1 & 11.1 \\
\hline
\end{tabular}


from $2.5 \%$ to $11.1 \%$ (Table 1 ). The three DtAALs were putatively designated as DtAAL $X$, DtAAL 7 and DIAAL 11. The morphological features of these DtAALs deviated from those of disomics and MtAALs. The extra pair of telocentric chromosomes incorporated in the diploid complement were identified by karyotype analysis. DtAAL X carried an additional pair of telocentric chromosomes with a medium length, while DtAALs 7 (Fig. 1) and 11 each had an additional pair of telocentric chromosomes with a short length.

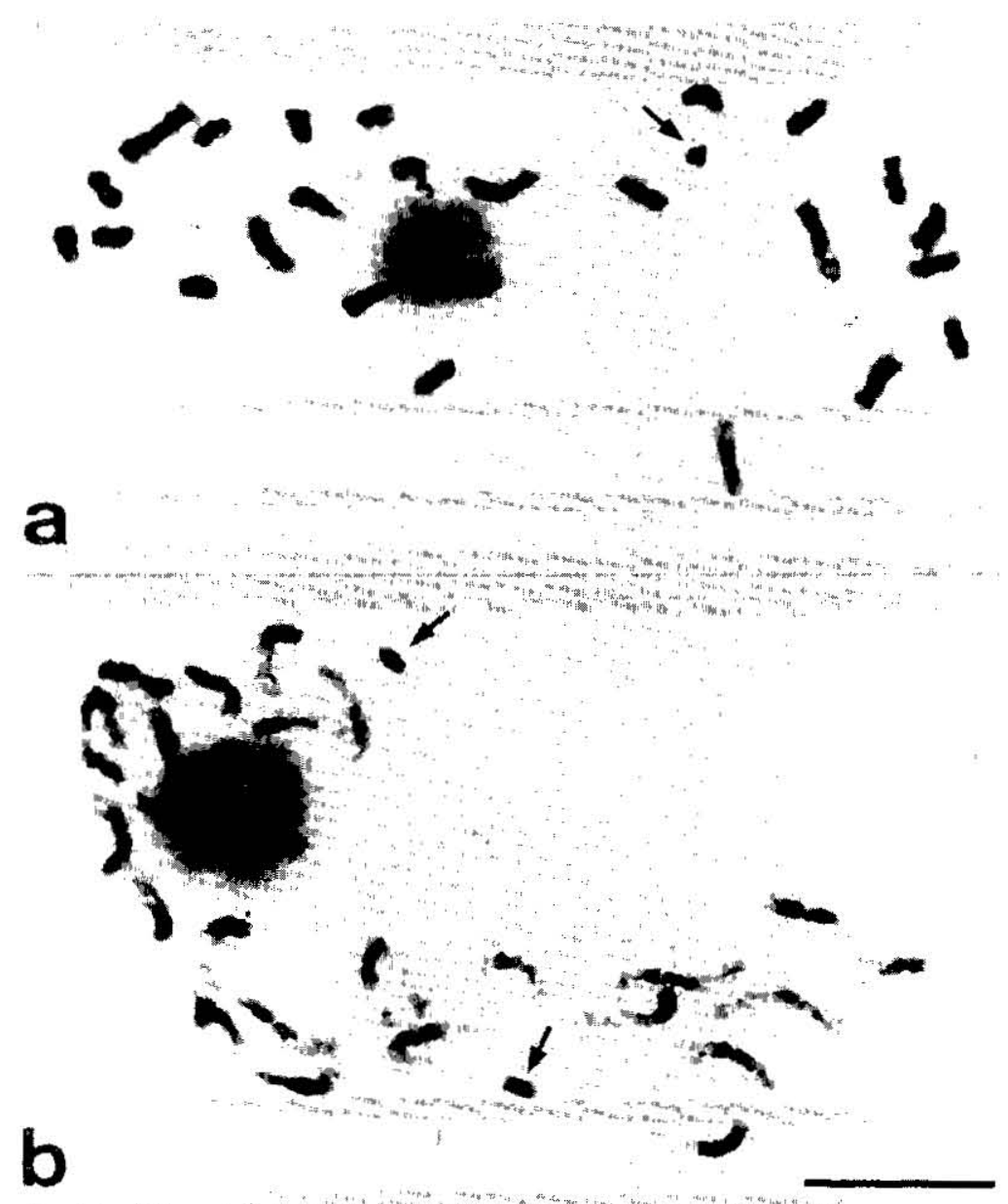

Fig. 1. Somatic metaphase chromosomes of a monotelosomic and a ditelosomic alicn addition lines in rice carrying chromosome(s) of $O$. punctata Kotschy (Genume: $2 n=2 x=B B$ ). (a) $2 n=24+1$ telocentric $7 \mathrm{~B}$ chromosome. (b) $2 n=24+2$ telocentric $7 B$ chromosomes. Arrows show telocentric $7 B$ chromosome(s). A bar $=5 \% \mathrm{~m}$. 


\section{Meiotic chromosome behavior}

The meiotic chromosome behavior were observed in DtAALs X, 7 and 11. The typical results are shown in Figures 2, 3 and 4. A telocentric bivalent with short length in addition to 12 bivalents with relatively long lengths were observed at the pachytene in all DtAALs (Figs. 2a, 3a and 4a, b). As shown in Table 2, more than $90 \%$ of the PMCs in the DtAALs formed $12 \mathrm{n}+1 \mathrm{t} \amalg$ (Figs. 2b, c, 3b, d and $4 \mathrm{c}, \mathrm{d}$ ) at the diakinesis and metaphase I

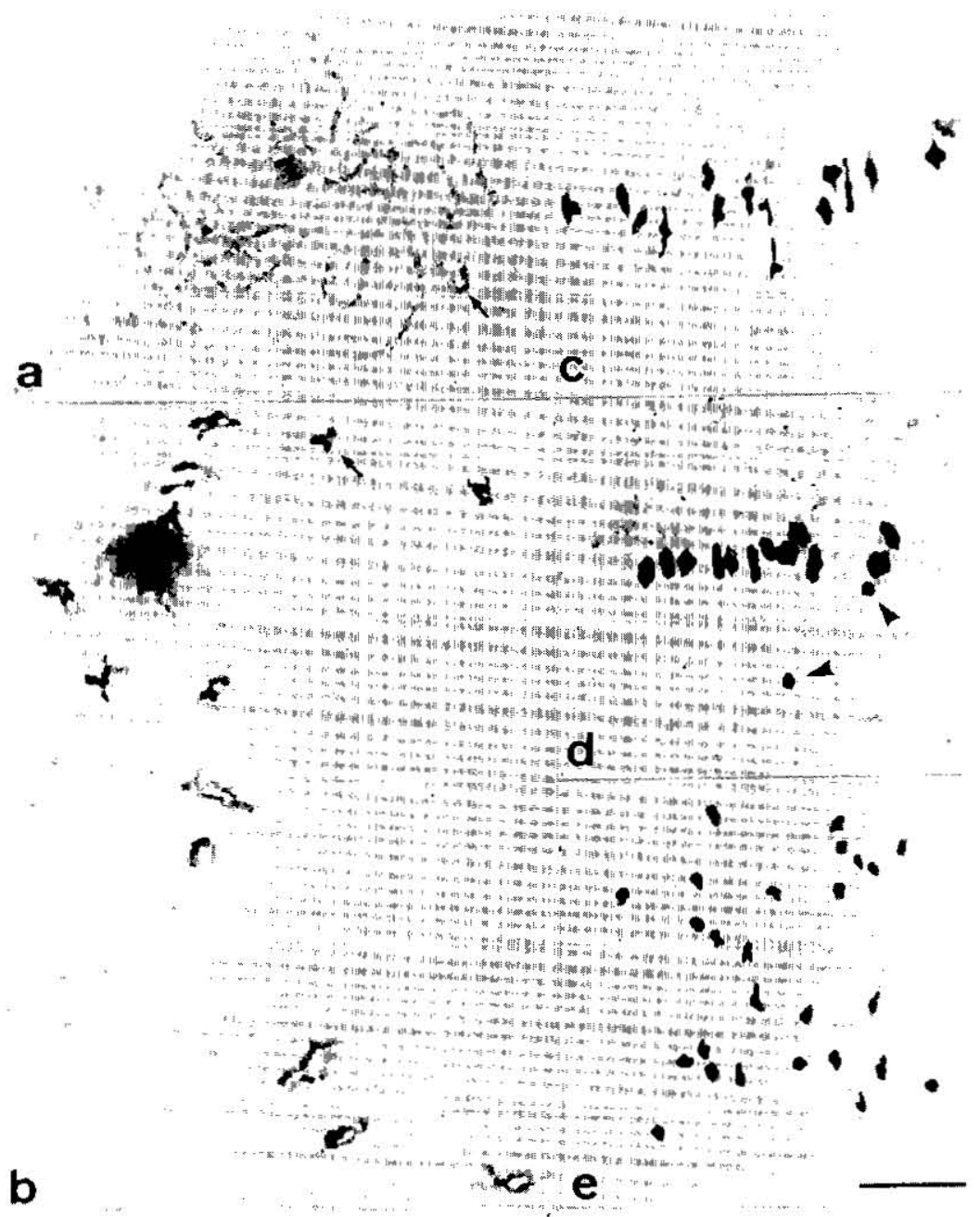

Fig. 2. Meiosis in ditclosomic alien addition line X. (d) A pachytene slage showing 12 II +1 til chromosome association; (b) An carly diakinesis showing $12 \pi+1$ tu chromosome association jncluding one telosomic bivalent; (c) A metaphase stage showing $12 n+1$ til chromosome association; (d) A metaphase stage showing $12 \mathrm{II}+2 \mathrm{tr}$ chrornosomc association; (e) An anaphase stage showing 13:13 segregation. Arrows and arrowheads show telocentric $O$. punctaic chromosome(s). A bar shows $5 \mu \mathrm{m}$. 


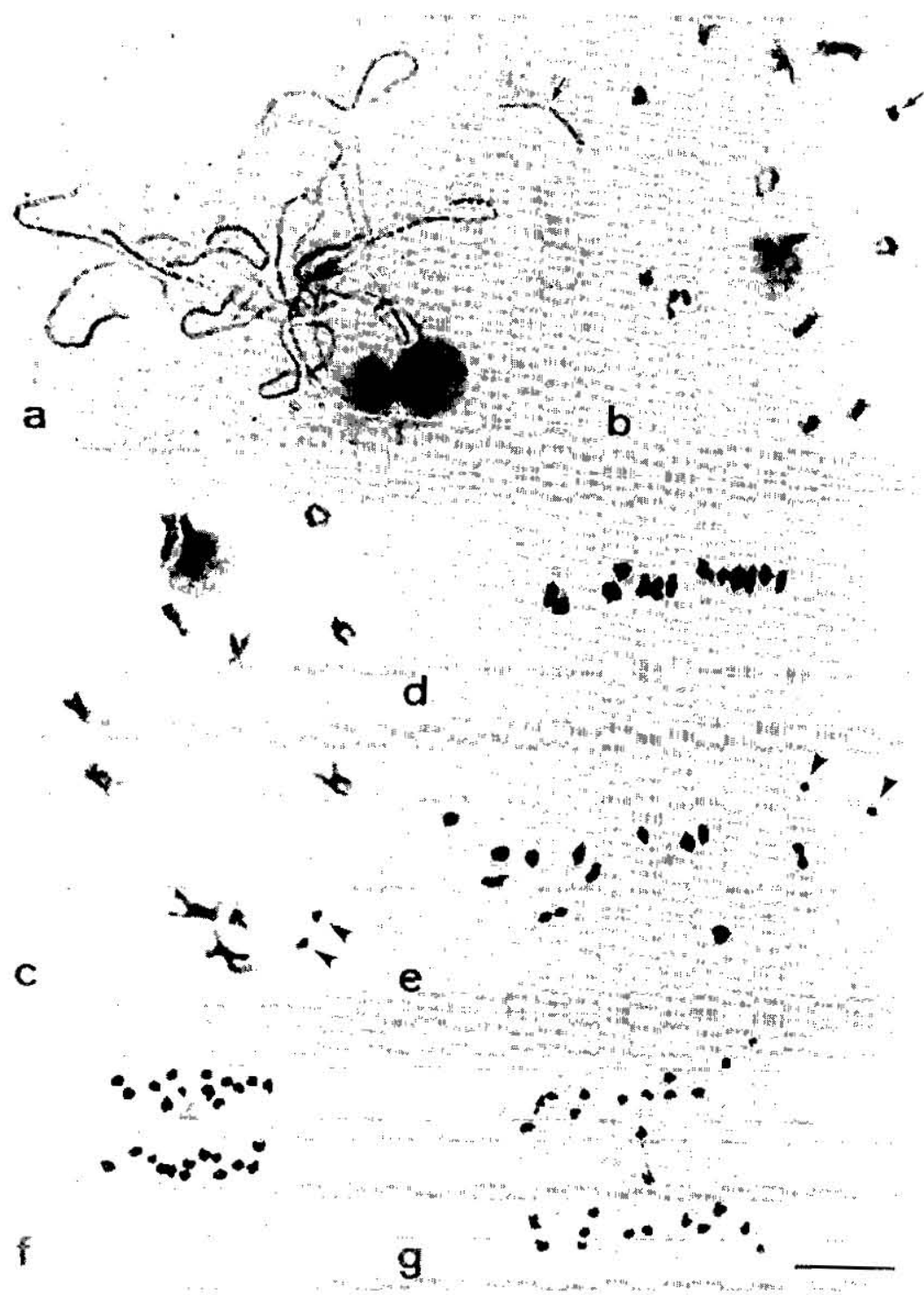

Fig. 3. Meiosis in ditelosomic alien addition line 7. (a) A pachytene stage showing 12I-1ti chromosome association; (b) An early diakinesis showing $12 \pi+11 . u$ chromosome association including one telosomic bivalent; (c) An early diakinesis showing $12 n+1$ tin chromosome association; (d) A metaphase stage showing $12 n+1$ tI chromosome association; (c) A metaphase stage showing $12 \pi+2 \mathrm{t}$ chromosome association; Anaphase stages showing 13:13 segregation (f) and with lagging chromosomes(g). Arrows and arrowheads show telocentric $7 \mathrm{~B}$ chromosome(s). A bar shows $5 \mu \mathrm{m}$. 


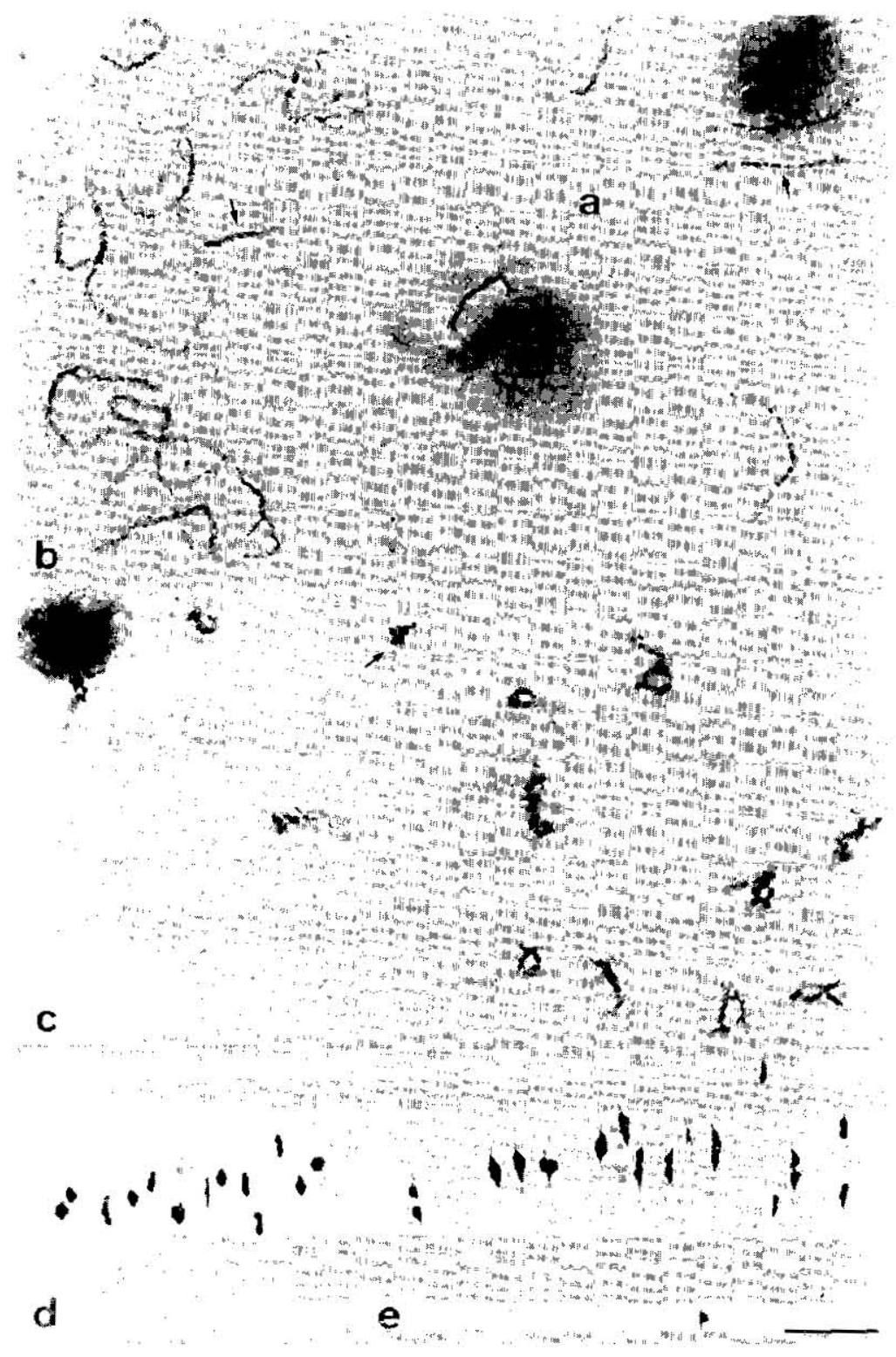

Fig. 4. Meiosis in ditelosomic alien addition line 11. (a, b) A pachytenc stage showing 12t:+1til chromosome association; (c) A diakinesis showing $12 n+1$ th chromosome association including onc telosomic bivalent; (d) A metaphase stage showing $12.1+11$ t chromosome association; $(e)$ A metaphase stage showing precocious segregation. Arrows show telocentric $11 \mathrm{~B}$ chromosome(s). A bar shows $5 \mu \mathrm{mi}$. 
while the rest being $12 \mathrm{~m}+2 \mathrm{t}$ (Figs. $2 \mathrm{~d}, 3 \mathrm{c}$, e and $4 \mathrm{e}$ ) showing frequently precocious separation. Most of the PMCs showed 13:13 segregation at anaphase I (Figs. 2e and 3f). Lagging chromosomes sometimes occurred at anaphase I (Fig. 2g).

Table 2. Meiotic chromosome behavior of three DtAALs each carrying a pair of 1.clocentric chromosomes of $O$. punctata Kotschy.

\begin{tabular}{|c|c|c|c|c|c|c|}
\hline \multirow{2}{*}{$\begin{array}{l}\text { Jitelosomic } \\
\text { alien addition } \\
\text { lone }\end{array}$} & \multirow[b]{2}{*}{ Stage: } & \multicolumn{4}{|c|}{ Number of PMCs } & \multirow{2}{*}{$\begin{array}{l}\% \text { of } \\
12 u \\
+1 t u\end{array}$} \\
\hline & & $\begin{array}{r}12 \mathrm{II} \\
+1 \text { tI }\end{array}$ & $\begin{array}{r}12 . \mathrm{I} \\
+2 \mathrm{t} I\end{array}$ & Others & Total & \\
\hline \multirow[t]{2}{*}{ DtAAL X } & DK & 82 & 1 & 0 & 83 & 98.8 \\
\hline & MI & 101 & 9 & 2 & 112 & 90.2 \\
\hline \multirow[t]{2}{*}{ 1)tAAL 7} & DK & 111 & 2 & 0 & 113 & 98.2 \\
\hline & MI & 79 & 4 & 2 & 85 & 92.9 \\
\hline \multirow[t]{2}{*}{ DIAAL 11} & I)K & 35 & 0 & 0 & 35 & 100.0 \\
\hline & $\mathrm{Ml}$ & 61 & 1 & 2 & (3) 4 & 95.3 \\
\hline
\end{tabular}

a) Dk; diakinesis, MI; metaphase 1 .

b) Two PMCs of each ditelosomic alien addition line showed precocious separation at Mi.

\section{Morphological features and pollen and seed fertility}

The diagnostic characteristics as well as pollen and seed fertility of the DtAALs X, 7 and 11 are shown in Table 3. The degrees of morphological deviation of the three DtAALs from disomic plants were more intersified than those of the parental MtAALs. DtAAL $X$ showed more slender kernels than the parental MtAAL. DtAAL 7 was characterized by

Table 3. Comparison of morphological and reproductive features of MtAALs and DtAALs each carrying single or a pair of chromosome(s) of $O$. punctata Kotschy.

\begin{tabular}{|c|c|c|c|}
\hline Line & Diagnostic morphological features & $\begin{array}{l}\text { Pollen } \\
\text { fertility } \\
\qquad(\%)\end{array}$ & $\begin{array}{l}\text { Seed } \\
\text { fertility } \\
(\%)\end{array}$ \\
\hline MtAAL X & $\begin{array}{l}\text { Semi-dwarf, semi-lax panicles, serni-rolled } \\
\text { leaves, narrow grains with tiny awt }\end{array}$ & 91.2 & 85.5 \\
\hline DtAßL $\mathrm{X}$ & $\begin{array}{l}\text { Dwarf, lax panicles, rolled leaves, } \\
\text { narrow grains with tiny awr }\end{array}$ & 66.0 & 14.2 \\
\hline M1AAL 7 & $\begin{array}{l}\text { Semi-short panicles, semi-round grains, } \\
\text { slightly brown pericarp }\end{array}$ & 89.7 & 93.3 \\
\hline DtAAL 7 & $\begin{array}{l}\text { Short yanicles, round grains, } \\
\text { darkish brown pericarp }\end{array}$ & 82.4 & 78.6 \\
\hline MLAAL $] 1$ & $\begin{array}{l}\text { Pseudo-normal, slightly compact panicles, } \\
\text { grains with pointed apiculi }\end{array}$ & $>90.0^{*}$ & 95.6 \\
\hline DtAAL 11 & $\begin{array}{l}\text { Compact panicles, slender grains } \\
\text { with pointed apiculi }\end{array}$ & $>90.0^{*}$ & 91.9 \\
\hline Disomics & Normal & $>90.0^{*}$ & 93.8 \\
\hline
\end{tabular}

*Average of two sets of data taken at different years. 
more round kernels and more brownish pericarp than the parental MtAAL due to gene(s) located on chromosome 7 of $O$. punctala. DtAAL 11, on the other hand, has slender kernels than the parental Mt.AAL. In addition, the panicles of I)tAAL 11 were more incompletely exerted compared with the parental MtAAL. The pollen fertility of the three DtAALs were considerably high especially DtAAL 11 which was almost the same as the disomics. The seed fertility of DtAALs 7 and 11 can be classified high ( $78.6 \%$ and $91.1 \%$, respectively), while that of DtAAL $\mathrm{X}$ as low (14.2\%).

\section{Alien chromosome transmission}

Alien chromosome transmission of the three DtAALs were shown in Table 4. All of the three DtAALs were recovered in their self-pollinated progenies and more than $95 \%$ of the self-pollinated progenies each had at least one alien chromosome. DtAAL X showed complete transmission of the alien chromosome in the self-pollinated progeny.

Table 4. Clromosome stability in the self-pollinated progenies of DtAALs.

\begin{tabular}{|c|c|c|c|c|c|}
\hline \multirow{2}{*}{$\begin{array}{l}\text { Parental } \\
\text { [1.AAL }\end{array}$} & \multirow{2}{*}{$\begin{array}{l}\text { Number of } \\
\text { plants } \\
\text { identified }\end{array}$} & \multicolumn{3}{|c|}{ Number of plants } & \multirow{2}{*}{$\begin{array}{l}1 \% \text { of } \\
\text { MLAAL } \\
\text { TDLAAL }\end{array}$} \\
\hline & & $\begin{array}{l}\text { Disomics } \\
(2 n=24)\end{array}$ & $\begin{array}{l}\text { Mt.AAL } \\
(2 \mathrm{n}=25)\end{array}$ & $\begin{array}{l}1) \mathrm{A} A \mathrm{~L} \\
(2 \mathrm{n}=26)\end{array}$ & \\
\hline DtAAL X & 28 & 0 & 3 & 25 & 100.0 \\
\hline DtAAI, 7 & 41 & 2 & 11 & 28 & 95.1 \\
\hline TJAAL 11 & 29 & I & 2 & 26 & 96.6 \\
\hline
\end{tabular}

\section{DISCUSSION}

Three DtAALs of rice each carrying an extra pair of telocentric chromosomes of Oriyza punctata occurred at low frequencies (2.5-11.1\%) from the respective MLAALs X, 7 and 11. The aberrant plant types with the expression of chromosome-specific effects must have originated through the fertilization of male and female gametes each carrying a telocentric chromosome of $O$. punctata. At mciosis, the alien telocentric chromosomes of the three DtANLs fully paired at pachytene and usually separated to each daughter cell at anaphase I, giving rise to the viable gametes with the alicn telocentric chromosome at high frequencies. The transmission rates of the alien chromosome were considerably high in the DHAALs, while most plants in their self-pollinated progenies carrying at least one alien tclocentric chromosome. Pollen and seed fertility were different among DtAALs. DtAAL 11, carrying a short telocentric chromosome of $O$. punctata, showed high pollen and sced fertility similar to the disomics.

The three DtAALs of rice isolated in the present study can be used in transferring alien traits from $O$. pumctata to $O$ satima. These DtAALs showed relatively stable transmission of alien telocentric chromosome $(s)$, where gametes with an extra telocentric chromosome are functional both in female and male gametes. These facts suggest that. small chromosome fragments with functional centromere, that is a teloceritric 
chromosome, can be transmitted to the progenies with certain stability. In addition, pollen and seed fertility were considerably restored in the DtAALs carrying small fragments such as telocentric chromosomes 7 and 11 of 0 . punctata. The following procedures to develop materials for breeding program are, therefore: proposed: (1) The screening of MtAALs derived from spontaneous misdivision of the additional alien univalents in MAALs, and (2) the selection of fertile DtAAL stocks for the respective 24 chromosome arms of O. punctata.

\section{REFERENCES}

Fedak, G. and S. B. Helgason 1970 The cytogenetics of a dilelotetrasomic line in barley. Can. J. Genet. Cutol., 12: $553-559$

Lange, W., Th. S. M. De Bock and C. J. Speckmam 1993 Disomic and ditelosomic alien chromtosome additions in beet (Beta vulgaris), carrying an extra chromosome of $B$. procumbens or telosome of $B$. patellaris. Genome, 36: 261-267

Riley, R. and V. Chapman 1958 The production and phenotypes of wheat-rye chromosome addition lines. Heredity, 12:301-315

Tsuchiya, T. 1969 Cytogenetics of a new type of barley with 16 chromosomes. Chromosoma (Berl.), 26: 130-139

Wicbc, G. A. 1975 Eight-paired barley. Barley genetics, III: $242-246$

Yasui, H. and N. Iwata 1998 Development of monotelosomic and monoacrosomic alien addition lines of rice (Oryza satima L.) carrying a single chromosome of O. punctata Kotschy. Breed. Sci., 48: $181-186$

Yasui, H., N. Onta and N. Iwata 1995 Isolation of thirtcen-paired rice. Rice Genet. Newsl., 12: 215-217 